\title{
The Influence of Magnesium on Cell Division
}

\section{The Effect of Magnesium on the Growth of Bacteria in Simple Chemically Defined Media}

\author{
BY M. WEBB \\ Chemistry Department, The University, Edgbaston, Birmingham
}

\begin{abstract}
SUMMARY: In simple chemically defined media all of 15 bacteria failed to grow in the complete absence of magnesium. The concentration of magnesium for maximum growth was dependent upon the Gram reaction of the individual species examined, the magnesium requirements of the Gram-positive organisms being some ten times greater than the requirements of the Gram-negative organisms. In contrast to the observations made in more complex media (peptone water), normal cell division occurred in chemically defined media containing suboptimal amounts of magnesium. It is suggested that magnesium is involved in the synthesis of bacterial protoplasm as well as cell division and, in simple chemically defined media, the synthetic reactions require the higher magnesium concentration.
\end{abstract}

It has been shown (Webb, 1949) that magnesium is essential for the normal cell division of the rod-shaped bacteria growing in a peptone water medium, and that it also stimulates the growth of these organisms. The Gram-positive bacteria examined required a greater magnesium concentration for normal growth and cell division than did the Gram-negative bacteria. In an attempt to interpret these results quantitatively, a study was made of the effect of magnesium on the growth of bacteria in simple chemically defined media. The bacteria studied were those capable of growth in a mixture of salts and carbon compounds, all of which could be obtained free from magnesium. The presence of traces of magnesium in some of the components of the media probably explains the conflicting results obtained by earlier workers in this field (see Knight (1936) for a review). Studies by Lodge \& Hinshelwood (1939) on the growth of Bact. lactis aerogenes (Aerobact. aerogenes) in a chemically defined medium composed of pure salts and glucose, showed that small inocula would not grow in the absence of magnesium. For a given inoculum there was a limiting magnesium concentration, 1-20 parts per million (p.p.m.) according to the conditions of the experiments, below which no growth occurred and above which growth occurred normally. Moreover, the final population and, to a first approximation, the rate of growth was independent of the active amount of magnesium in excess of the limit.

In the present work, all the bacteria studied failed to grow in the complete absence of magnesium, but, in contrast to the results of Lodge \& Hinshelwood (1939) maximum growth occurred at a certain optimal magnesium concentration, and this optimum varied according to the Gram-staining reaction of the organism.

\section{MATERIALS AND METHODS}

Water used in the preparation of media was twice distilled in a Pyrex glass still and then redistilled immediately before use. Test-tubes were cleaned in chromic-sulphuric acid mixture, rinsed in sodium bicarbonate solution and then 
repeatedly washed in the distilled water. Pyrex glassware was used throughout, since media stored in soft glass vessels apparently dissolved magnesium from the glass.

The 'Analar' salts, glucose and glycerol used in the preparation of the media contained no detectable magnesium. Asparagine, used in place of aspartic acid in Koser \& Rettger's (1919) medium, contained some inorganic salts which proved difficult to remove. However, neither magnesium nor manganese could be detected in the ash ( $\equiv 5 \%$ of the asparagine preparation). In order to minimize the precipitation which occurs in simple chemically defined media, the phosphate solutions required were sterilized separately and added to the main bulk of the medium when cold.

To avoid the transfer with the inoculum of sufficient magnesium for growth and to adapt the organism to the medium, subcultures were made from stock into the defined medium containing no magnesium and incubated for $24 \mathrm{hr}$. Serial subcultures were then made into the same medium every $24 \mathrm{hr}$. until the final subculture failed to grow. Each tube of the experimental series was then inoculated with $0.01 \mathrm{ml}$. of the penultimate culture of this series of subcultures in the $\mathrm{Mg}$-deficient medium. The latter tubes were incubated at the optimum growth temperature until a stationary state was established. The amount of growth was then measured turbidimetrically by means of the Spekker adsorption photometer after the addition of $0.1 \mathrm{ml}$. of $10 \mathrm{~N}-\mathrm{HCl}$. Control experiments showed that with a uniform suspension of cells (Aerobacter aerogenes) the readings of the instrument below $1 \cdot 0$ were proportional to the number of cells.

\section{EXPERIMENTAL}

The influence of the magnesium concentration on the growth of those species examined which were able to grow in simple chemically defined media is shown in Figs. 1-7.

Owing to the thick pellicles formed by Bacillus vulgatus and Mycobacterium tuberculosis, the influence of magnesium was assessed qualitatively. B. vulgatus grown for $48 \mathrm{hr}$. in Koser \& Rettger's (1919) medium showed the following relative amounts of pellicle at the respective $\mathrm{Mg}$ concentrations (in p.p.m.) indicated:,$- 0 ;+, 5 ;++, 10 ;+++, 20,40$ and $50 ;+, 100$; where $+++=$ thick pellicle, $++=$ moderate pellicle, $+=$ thin film of growth, and $-=$ no growth. Similarly, $\boldsymbol{M}$. tuberculosis, human (a virulent laboratory strain), was grown for 8 days at $37^{\circ}$ in Long medium (Long \& Seibert, 1926), the inoculum being, per tube, a $2 \mathrm{~mm}$. square piece of 8-day pellicle grown on the same medium with $\mathrm{Mg}$ at $0.0005 \%(\mathrm{w} / \mathrm{v})$. The relative amounts of growth at the respective $\mathrm{Mg}$ concentrations (in p.p.m.) were:,$- 0 ;++, 5 ;+++, 50$, 100 and $200 ;++, 400 ;+, 500$; where $+++=$ surface covered, $++=$ surface $\frac{2}{3}$ covered, $+=$ surface $\frac{1}{3}$ covered, and $-=$ no growth.

All the bacteria examined failed to grow in the complete absence of magnesium. These results are in accordance with the findings of Robinson (1932) with Ps. pyocyaneus (Ps. aeruginosa) and of Lockemann (1919), Frouin \& Guillaumie (1928) and Model (1929) with $M$. tuberculosis in chemically defined media. 
Cultures of Ps. prunicola and Serratia marcescens in media containing suboptimal amounts of magnesium were characterized by increased polysaccharide synthesis as indicated by the high viscosity of the cultures.

In contrast, magnesium appeared to be completely unessential for the growth of certain strains of soil actinomyces and of Thiobacillus thiooxidans. These organisms continued to grow in the absence of magnesium after 20 subcultures in chemically defined media prepared according to Conn \& Conn (1941) and Waksman (1922), respectively.

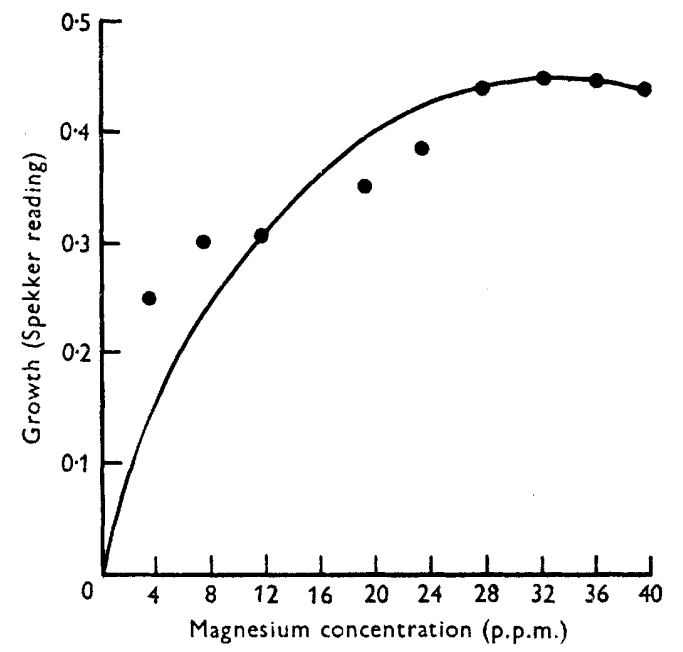

Fig. 1. Effect of magnesium on the growth of Azotobacter chroococcum (Burk's (1930) medium).

The curves relating magnesium concentration to the mass of growth of various organisms (Figs. 1-7) differ from those obtained by Lodge \& Hinshelwood (1939) for Aerobact. aerogenes. Under the present experimental conditions, Aerobact. aerogenes attained maximal growth in two different media when the magnesium concentration was of the order of 2-3 p.p.m. Only when the initial $\mathrm{pH}$ value of the medium was low ( $\mathrm{pH} 4.7$ ) was the amount of growth apparently independent of the magnesium concentration (Fig. 4). However, in this case, growth was limited by the final $\mathrm{pH}$ of the medium, since all cultures covering the range of magnesium concentration had a final constant $\mathrm{pH}$ value $(\mathrm{pH}$ 3.46-3.53). Furthermore, when the medium was initially adjusted to $\mathrm{pH} \mathbf{3} \cdot \mathbf{4}$, Aerobact. aerogenes failed to grow, irrespective of the magnesium concentration.

Certain of the bacteria studied (e.g. Serratia marcescens, Aerobact. aerogenes) grew in media in which the only inorganic cations were $\mathrm{K}$ and $\mathrm{Mg}$ (together with ammonia as nitrogen source). Similarly, Katznelson (1947) has shown that K, $\mathbf{M g}$ and $\mathbf{P}$ are the only inorganic elements necessary for the growth of $\boldsymbol{B}$. polymyxa in a defined medium. The presence in the Analar salts of other functionally active metallic ions such as, for example, $\mathrm{Fe}$, in concentrations sufficient for growth cannot, however, be excluded (cf. Waring \& Werkman, 1943).

In the present experiments neither Gram-positive nor Gram-negative 
bacteria grew as filaments in the chemically defined media containing suboptimal amounts of magnesium. Only in cultures of certain Gram-negative bacteria (e.g. Ps. prunicola, Aerobact. aerogenes) in media containing the higher magnesium concentrations used (8-10 p.p.m.) were filamentous cells observed.

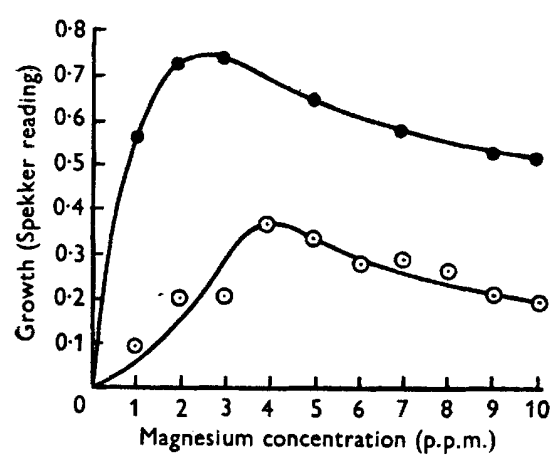

Fig. 2

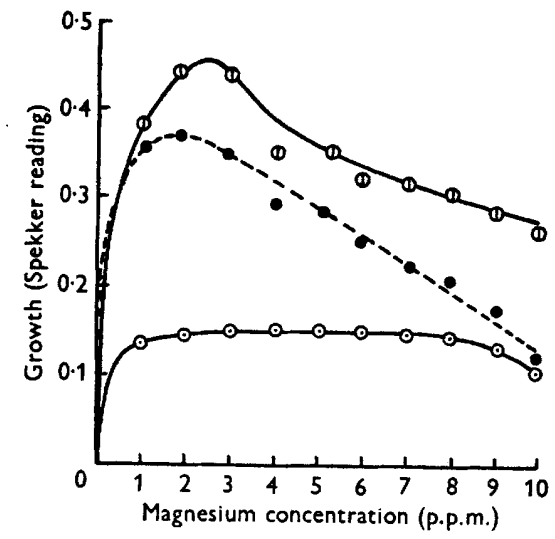

Fig. 4

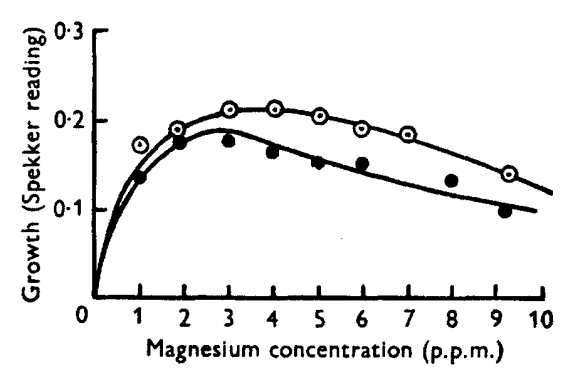

Fig. 3

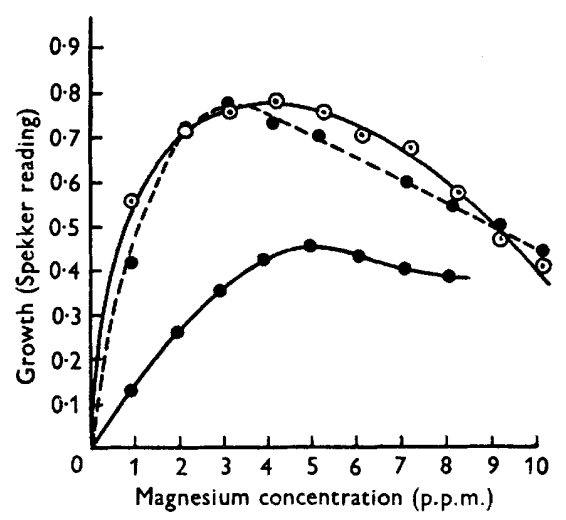

Fig. 5

Fig. 2. Effect of magnesium on the growth of Pseudomonas aeruginosa (O-O) and Ps. prunicola $(\mathrm{O}-\mathrm{O})$ (Erikson's (1945) medium).

Fig. 3. Effect of magnesium on the growth of Alcaligenes faecalis (-) and Escherichia coli-commune (O-O) (Koser \& Rettger's (1919) medium).

Fig. 4. Effect of magnesium on the growth of Aerobacter aerogenes. $0-0$ medium of Lodge \& Hinshelwood (1939). pH 4.7. (1)-(1) medium of Lodge \& Hinshelwood (1939). pH 6.5. -.. medium of Koser \& Rettger (1919). pH 6.8.

Fig. 5. Effect of magnesium on the growth of Aerobacter cloacae (-), Esch. coli var. acidilactici (-.-O) and Chromobact. violaceum $\left(\mathrm{O}_{-} \mathrm{O}\right)$ in Koser \& Rettger's (1919) medium.

On increasing further the magnesium concentration the incidence of filaments was increased. Thus cultures of $\boldsymbol{P} s$. prunicola in Erikson's (1945) medium containing $0.5 \%(\mathrm{w} / \mathrm{v}) \mathrm{Mg}$ grew as tangled filaments and microscopic examination failed to reveal any single short cells. In contrast, filaments were never observed with the Gram-positive species examined in cultures containing 
magnesium in excess of the optimal concentration for growth. Such concentrations (e.g. 100 p.p.m.) often more or less completely inhibited the growth of the organisms (Fig. 7).

\section{DISCUSSION}

Figs. 2-5 show that the Gram-negative bacteria studied reach maximum growth when the magnesium concentration is of the order of 2-4 p.p.m. In contrast, maximum growth of the Gram-positive bacilli examined occurred at a magnesium concentration of 20-40 p.p.m. (Fig. 7). At concentrations of

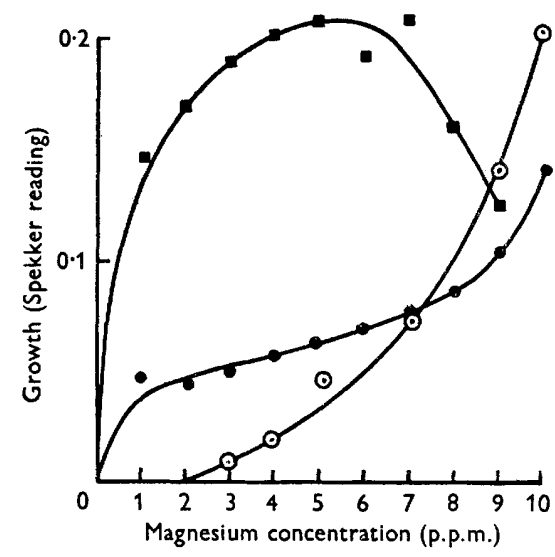

Fig. 6

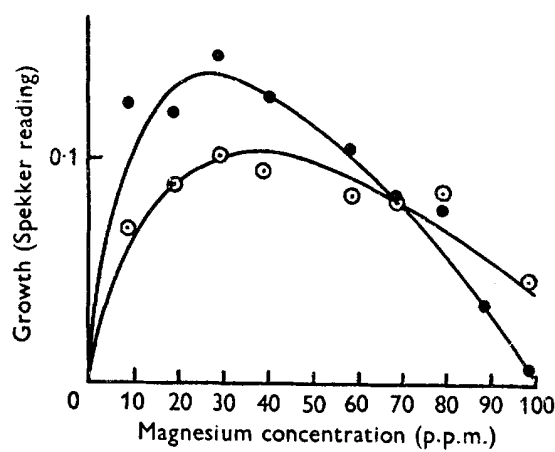

Fig. 7

Fig. 6. Effect of magnesium on the growth of Serratia marcescens ( $-\mathbf{E}$ ), medium of Shear, Turner, Perrault \& Shovelton (1943), Bacillus subtilis var. viscosus (-) and B. polymyxa (○-○) (Koser \& Rettger's (1919) medium).

Fig. 7. Effect of magnesium on the growth of B. mycoides $(\bigcirc-\bigcirc)$ and B. subtilis in Koser \& Rettger's (1919) medium.

magnesium which were optimal for the Gram-negative bacteria the growth of the Gram-positive bacteria was only a fraction of the maximum value (Fig. 6). Although the relatively small number of species studied does not justify generalization, it would appear from these and previous results (Webb, 1949) that Gram-positive bacilli require a much greater concentration of magnesium for optimal growth than do Gram-negative bacteria. This difference can be attributed to the fact that the Gram-positive organisms incorporate magnesium into the structure of the Gram complex.

The fact that growth in simple chemically defined media is a function of the magnesium concentration and that no growth occurs at zero concentration suggests that magnesium is essential for the synthesis of bacterial protoplasm. Magnesium is also essential for the normal activity of the cell-dividing mechanism (Webb, 1949). Hence in the development of a normal bacterial population, magnesium takes part in (1) the synthesis of substances intermediate in composition between the foodstuff provided and the bacterial protoplasm, and (2) cell division. Furthermore, it is conceivable that in a complex medium which contains preformed components of protoplasm, such 
as amino-acids and other essential metabolites, a deficiency of magnesium would predominantly affect the process of cell division and not that of synthesis of protoplasm. On the other hand, in a simple chemically defined medium, on which an organism which was a good synthesizer could grow, magnesium would be essential both for synthesis of cell substance and for cell division. Under these conditions of growth, synthesis precedes cell division and, presumably, requires the higher magnesium concentration. That is, at concentrations of magnesium below the optimum for growth, normal cell division occurs throughout the restricted population that the medium is able to support. Only at relatively high and partially inhibitory concentrations of magnesium is the balance between growth and cell division altered to such an extent that filamentous cells are formed, i.e. cell division is impeded by the high magnesium concentration.

Thanks are due to Professor M. Stacey for his interest in this work, to Dr C. N. Iland for his co-operation in the experiments with $M$. tuberculosis, and to the Medical Research Council for a grant in aid of the expenses.

\section{REFERENCES}

Burk, D. (1930). The influence of nitrogen gas upon the organic catalysis of nitrogen fixation by Azotobacter. J. phys. Chem. 34, 1174.

Conn, H. J. \& Conv, J. E. (1941). Value of pigmentation in classifying Actinomycetes. J. Bact. 42, 791.

Erikson, D. (1945). Certain aspects of resistance of plum trees to bacterial canker. I. Some biochemical characteristics of Pseudomonas mors-prunorum (Wormald) and related phytopathogenic bacteria. Ann. appl. Biol. 32, 44.

Frours, A. \& Guillaumie, M. (1928). Culture du bacille tuberculeux sur milieux synthétiques. Essai de généralisation de la notion d'équilibre entre les éléments constitutifs des milieux de culture. Ann. Inst. Pasteur, 42, 667.

Katznelson, H. (1947). Studies with Bacillus polymyxa. V. Potassium as a factor in the production of 2:3-butane-diol from starch. Can. J. Res. $25 c, 129$.

Knight, B. C. J. G. (1936). Bacterial nutrition. Material for a comparative physiology of bacteria. Spec. Rep. Ser. med. Res. Coun., Lond., no. 210.

Koser, S. A. \& Rettger, L. F. (1919). Studies on bacterial nutrition. The utilisation of nitrogenous compounds of definite chemical composition. J. infect. Dis. 24, 301.

Lockemans, G. (1919). What substances are absolutely necessary for the growth of the tubercle bacillus? Zbl. Bakt. Abt. 1, 83, 420 .

Lodge, R. M. \& Hrnshelwood, C. N. (1939). Physicochemical aspects of bacterial growth. V. Influence of magnesium on the lag phase in the growth of Bact. lactis aerogenes in synthetic media containing phosphate. J. chem. Soc. p. 1692.

Long, E. R. \& Seibert, F. B. (1926). The chemical composition of the active principle of tuberculin. I. A non-protein medium suitable for the production of tuberculin in large quantity. Amer. Rev. Tuberc. 13, 393.

Model, L. M. (1929). Biochemistry of nutrition and growth of tubercle bacilli. Zhur. exp. biol. Med. 12, 274. (Chem. Abstr. 1930, 24, 1881.)

Robinson, G. L. (1932). The growth of B. pyocyaneus in synthetic media. Brit. J. exp. Path. 13, 310.

Shear, M. J., Turner, F. C., Perrault, A. \& Shovelton, T. (1943). Chemical treatment of tumours. Isolation of the haemorrhage-producing fraction from Serratia marcescens (Bacillus prodigiosus) culture filtrate. J. Nat. Cancer Inst. 4, 81. 
Waksman, S. A. (1922). Micro-organisms concerned in the oxidation of sulphur in the soil. IV. A solid medium for the isolation and cultivation of Thiobacillus thio-oxidans. J. Bact. 7, 605.

WARING, W. S. \& WERKMAN, C. H. (1943). Iron requirements of heterotropic bacteria. Arch. Biochem. 1, 425.

Webs, M. (1949). The influence of magnesium on cell division. 2. The effect of magnesium on the growth and cell division of various bacterial species in complex media. J. gen. Microbiol. 3, 410. 